This paper is published in the open archive of Mid Sweden University

DIVA http://miun.diva-portal.org

with permission of the publisher

Citation for the peer-reviewed published paper:

Bäckström M, Hammar L, Htun M. Beatability and runnability studies of ion-exchanged unbleached kraft pulps on a pilot scale. ; Nordic Pulp \& Paper Research Journal. 2009;24(1):94-100.

URL to article at publishers site:

http://dx.doi.org/10.3183/NPPRJ-2009-24-01-p094-100 


\title{
Beatability and runnability studies of ion-exchanged unbleached kraft pulps on a pilot scale
}

\author{
Marie Bäckström, Lars-Åke Hammar and Myat Htun*, STFI-Packforsk AB, Stockholm, Sweden
}

KEYWORDS: Beating, Refining, Swelling, Kraft pulps, Mechanical properties

\begin{abstract}
SUMMARY: It has earlier been shown that the counter-ion to the charged groups in the fibre has a significant effect on the beatability of fibres, but large-scale investigations of this effect are scarce in the literature. The objectives of the present study were therefore to develop a technique to ion-exchange large quantities of industrial pulp into the $\mathrm{Na}^{+}$-form using complexing agents and to study the effect of industrial-scale refining on pulp fibres in the $\mathrm{Na}^{+}$-form and how the fibres respond to industrial-like papermaking.

The results show that ion-exchange can indeed be conducted on a pilot-scale using complexing agents such as DTPA. The study further indicates that an energy reduction of $50 \%$ at a given WRV or tensile index may be achieved if the fibres are converted to $\mathrm{Na}^{+}$-form prior to pilot-scale refining. By applying these techniques in full-scale production, it should thus be possible to save significant amount of energy, especially in the case of papers made from unbleached pulp that usually demands a higher degree of beating to achieve sufficient strength.
\end{abstract}

ADDRESSES OF THE AUTHORS: Marie Bäckström

(marie.backstrom@stfi.se), Lars-Åke Hammar

(larsake.hammar@stfi.se) and Myat Htun (myat.htun@stfi.se): STFI-Packforsk AB, Box 5604, SE-114 86 Stockholm, Sweden. * Also associated with Mid Sweden University.

Corresponding author: Marie Bäckström

It is known that the counter-ions to the charged groups in the fibres play an important role in their swelling ability (Lindström, Carlsson 1978; Scallan, Grignon 1979; Scallan 1983; Lindström, Carlsson 1982; Lindström 1992). Electrostatic repulsion of negatively charged groups is the cause of swelling according to the theory of charged electrolytic gels (Flory 1953). It has been shown in the literature that handsheets made from fibres with carboxyl groups in different ionic forms have different tensile indexes, where fibres in the $\mathrm{Na}^{+}$-form had the highest tensile index and swelling ability while hydrogen and aluminium counter-ions gave less swelling and poorer strength (Scallan, Grignon 1979).

The counter-ion to the charged groups in the fibre has also been reported to have a significant effect on the beatability of fibres in laboratory studies (Lindström, Kolman 1982; Hammar et al. 2000). Hammar et al. (2000) separated the effects of counter-ion on refining and sheet moulding by converting all the fibre samples after laboratory Escher-Wyss refining into the $\mathrm{Ca}^{2+}$-form prior to handsheet-making. Their results showed that the energy required to reach a given WRV value or a given tensile index could be reduced by $50 \%$ by the ionexchange of the fibre charges.

Laboratory refining is normally performed with recirculation of the pulp, i.e the fibre suspension is passing through the refiner multiple times while industrial refining is normally performed as single stage refining. The property developments of pulp fibres in laboratory refiners differs from industrial refiners and have been suggested to originate from differences in homogeneity of the fibre treatments or differences in fibre shortening between different refiners. Mohlin (1991) have studied industrial and laboratory refining and have found that the main reason for differences in refining response between laboratory and industrial refining is that laboratory refiners are more effective in fibre straightening.

The conversion of pulp fibre charges to different ionic forms requires several ion-exchange and washings stages. In the laboratory the metal ions within the pulp must first be removed by acid washing and the excess of acid must then be removed. The fibres are then converted to the desired ionic forms, e.g. ion-exchanged into the sodium form by the addition of sodium hydroxide and the excess of sodium hydroxide is then removed by washing. This washing procedure is not feasible in larger-scale trials or industrial applications.

With this background, the objectives of the present study were two-folded. Firstly, it was necessary to develop a technique to ion-exchange large quantities of industrial pulps into $\mathrm{Na}^{+}$-form using complexing agents in a similar way as with pulps prior to bleaching with e.g hydrogen peroxide (Dence, Omori 1986). A laboratory study was therefore carried out to study how different process conditions affect the ion-exchange process when using the complexing agent DTPA. A series of experiments were conducted to study the effects of $\mathrm{pH}$ and of amount of DTPA, and the effect of the white water used during the ion-exchange.

Secondly, the objective was to study the property development of pulp fibres with their charges in the $\mathrm{Na}^{+}$-form on a more industrial scale by performing large pilot single-stage refining experiments and studying how the fibres produced responded to industrial-like papermaking on a pilot paper machine. The trial was performed at the pilot research paper machine EuroFEX at STFI-Packforsk.

\section{Materials and Methods}

\section{Materials}

Two industrial unbleached softwood (mixtures of pine and spruce) kraft pulps were used. For the laboratory study, a never-dried unbleached pulp from Skärblacka mill, Billerud was used. The kappa number of the pulp was 50 and the content of acid groups was $116 \mathrm{mmol} / \mathrm{kg}$. For the pilot study, a dried unbleached softwood pulp from Kemi pulp mill, Metsä Botnia was used. The kappa 
number of the pulp was 31 and the content of acid groups was $98 \mathrm{mmol} / \mathrm{kg}$.

Coplexing agent; DTPA, Diethylenetriaminepentaacetic acid, pentasodium salt, DTPA$\mathrm{Na}_{5}$ (Dissolvine D-40-K) from Akzo Nobel Rexolin AB was delivered as a $40 \%$ clear yellowish liquid.

In the laboratory trials deionised water and municipal water (tap water) from the water supply of Stockholm city were used. In the pilot trial, softened water and municipal water from the water supply of Stockholm city were used. The Stockholm city water has a hardness of $4-6^{\circ} \mathrm{dH}$ (29-43 $\mathrm{mg} / \mathrm{L}$ calcium) and is considered as moderately soft. It has a conductivity of $25 \mathrm{mS} / \mathrm{m}$. Softened water was obtained by sodium ion-exchange of the municipal water and contains no or only few calcium and magnesium metal cations.

\section{Laboratory ion-exchange study}

The ion-exchange was performed by adding DTPA to a suspension of fibres at $3.5 \%$ pulp consistency for 30 minutes at ambient temperature. Fig 1 shows the different procedures. The first set of experiments was conducted to clarify the sensitivity to $\mathrm{pH}$-changes, and the second trial to investigate the effect of different charges of DTPA (based on the amount of multivalent metal content determined by metal analyses) on the ion-exchange capacity. The third set of experiments was to study the importance of white water quality, i.e does the ion-exchange require deionised water or can it be performed in municipal water? After ion-exchange, the DTPA was removed by washing (see Fig 1). Approximately $40 \mathrm{ml}$ washing liquor/g pulp was used.

\section{Pilot refining trial}

Ion-exchange procedure

The ion-exchange of the pulp was done with softened water instead of deionised water in large storage tanks. No washing of the pulp before or after the DTPA charge was performed. DTPA (Dissolvine D-40-K) was added to the pulp at $3.0 \%$ pulp consistency. The addition of DTPA was stochiometric to the amount of multivalent ions (determined by metal analyses) in the pulp and the pulp suspension was left overnight for approximately 18 hours. The change in metal content due to the ionexchange is shown in Table 1. The amount of $\mathrm{Na}^{+}$was rather low in the untreated pulp. Treatment with DTPA increased the amount of $\mathrm{Na}^{+}$and decreased the amount of divalent ions such as $\mathrm{Ca}^{2+}$. Apart from the metal ions shown in the table, the untreated pulp contained a small
Table 1. Metal content of the pulp before and after ion exchange. The numbers in parentheses are $\mathrm{mmol} / \mathrm{kg}$.

\begin{tabular}{lcc}
\hline Metal & Untreated, meq/kg & Treated pulp, meq/kg \\
\hline $\mathrm{Ca}^{2+}$ & $74(37)$ & $24(12)$ \\
$\mathrm{Mg}^{2+}$ & $20(10)$ & $24(12)$ \\
$\mathrm{Mn}^{2+}$ & $2(1)$ & - \\
$\mathrm{Na}^{+}$ & $7(7)$ & $83(83)$ \\
\hline Total & $103(55)$ & $131(107)$ \\
\hline
\end{tabular}

amount of iron $(0.2 \mathrm{mmol} / \mathrm{kg})$. Besides iron, the untreated and treated pulps contained low amounts of silicon, zink and barium. There was also a small difference in mequivalents $/ \mathrm{kg}$ between the treated and untreated pulp. The treated pulp had a somewhat higher metal content than the untreated pulp and also somewhat more charges than determined by conductometric titration (98 $\mathrm{mmol} / \mathrm{kg}$ ). A possibly explanation for this might be insufficient washing prior to metal analysis to remove DTPA or the presence of oxides in addition to the charged groups.

\section{Refining}

The pilot refining was done in softened water for the ionexchanged pulp and in municipal water (tap water) from the city of Stockholm water supply for the reference pulp. The refining was performed at a specific edge load of $1.9 \mathrm{Ws} / \mathrm{m}$ in a 24 " Voith DD refiner as single stage refining. The flows were: 1380,825 and $590 \mathrm{l} / \mathrm{min}$. The refining consistency was $3 \%$, the initial temperature was $20^{\circ} \mathrm{C}$, and the $\mathrm{pH}$ was approximately 8 for the DTPAtreated pulp in $\mathrm{Na}^{+}$-form and 7 for the reference pulp in $\mathrm{Ca}^{2+}$. The conductivity of the fibre suspension refined in 
$\mathrm{Na}^{+}$-form was $800 \mathrm{mS} / \mathrm{cm}$ and of fibre suspension in the $\mathrm{Ca}^{2+}$-form $300 \mathrm{mS} / \mathrm{cm}$. Approximately $1000 \mathrm{~kg}$ of pulp was produced at each refining level.

\section{EuroFEX paper machine}

Paper was produced on the research paper machine EuroFEX at STFI-Packforsk, equipped with two short circulations and a closed white water system (Roding and Norman 1986). The water used in the trial was municipal water from the water supply of Stockholm city.

Paper with a grammage of $80 \mathrm{~g} / \mathrm{m}^{2}$ was produced on the roll former unit at a machine speed of $400 \mathrm{~m} / \mathrm{min}$. The forming consistency was $0.45 \%$. Similar conditions were used for all the trials. The jet/wire ratio was 1.1 (- $40 \mathrm{~m} / \mathrm{min})$.

The press section of the EuroFEX consists of one double felted roll press followed by two SymBelt presses (Rigdahl et al. 2000). The rolls in the two shoe presses are inverted in relation to each other. The linear load in the first press was $60 \mathrm{kN} / \mathrm{m}$ and the linear loads in the second and third presses were between 100 and 700 $\mathrm{kN} / \mathrm{m}$. The papers were dried in an off-line single dryer under tension in both MD and CD.

\section{Analysis of pulps and papers}

The kappa number of the pulps was determined according to IS0 302 and the fines content was measured using BDDJ (Britt Dynamic Drainage Jar), according to Tappi T261 cm-94. The shape factor, fibre length and fibre width were measured with the STFI FiberMaster (Karlsson et al. 1999). The WRV (Water Retention Value) was determined according to SCAN $-\mathrm{C}$ 62:00 except that deionized water was used. In the laboratory investigation, WRV both with and without fines material was determined. $2.2 \mathrm{~g}$ of fibres were decrilled using $2.5 \mathrm{dm}^{3}$ deionised water in a BDDJ having a sieve (125P) of $75 \mu \mathrm{m}$ (200 mesh). The sheet density was determined according to SCAN P-88:01, the tensile properties according to ISO 1924-3 and the tear resistance according to ISO 1974:1990. The Scott Bond values were evaluated according to TAPPI $833 \mathrm{pm} 94$. The primary data from the physical testing of the sheets were treated as recommended in SCAN-G 2:63, within a 95\% confidence interval.

The acid group content was determined by conductometric titration with $\mathrm{NaOH}$ (Katz et al. 1984; Lloyd, Horne 1993; Pu, Sarkanen 1989).

Metal analysis was performed using plasma-emission spectrometry, ICP-AES. Before the metal analysis was made, the pulp fibres were washed in order to remove the excess DTPA, while the metal ions attached to the charged groups in the fibres should remain in the pulp.

The formation spectra of the sheets produced were evaluated using a beta radiogram method (Norman 1986). The measurement gives the formation number, i.e the coefficient of variation of local grammage in the wavelength interval 0.3 to $30 \mathrm{~mm}$. The total formation number can be divided into a small-scale formation number in the wavelength interval $0.3-3 \mathrm{~mm}$ and a large-scale formation number in the interval $3-30 \mathrm{~mm}$.
Table 2. Metal content of unbleached pulp after ion exchange with DTPA at different $\mathrm{pH}$ levels. The DTPA was added in equivalent amount as mol multivalent ions in the fibres. The numbers in parentheses are $\mathrm{mmol} / \mathrm{kg}$.

\begin{tabular}{lccccc}
\hline $\begin{array}{l}\text { lon exchange at } \mathrm{pH} \\
\mathrm{meq} / \mathrm{kg}\end{array}$ & $\begin{array}{c}\mathrm{Na} \\
\mathrm{meq} / \mathrm{kg}\end{array}$ & $\begin{array}{c}\mathrm{Ca}, \\
\mathrm{meq} / \mathrm{kg}\end{array}$ & $\begin{array}{c}\mathrm{Mg}, \\
\mathrm{meq} / \mathrm{kg}\end{array}$ & $\begin{array}{c}\mathrm{Mn}, \\
\mathrm{meq} / \mathrm{kg}\end{array}$ & Total \\
\hline Ref, untreated & $26.1(26.1)$ & $99.4(49.7)$ & $22.4(11.2)$ & $4.0(2.0)$ & 151.9 \\
7 & $89.6(89.6)$ & $6.4(3.2)$ & $12.4(6.2)$ & $0.6(0.3)$ & 109 \\
9 & $101.7(101.7)$ & $1.4(0.7)$ & $8.6(4.3)$ & $0.6(0.3)$ & 112.3 \\
10 & $103.0(103)$ & $1.4(0.7)$ & $8.8(4.4)$ & $0.6(0.3)$ & 113.8 \\
11 & $105.2(105.2)$ & $1.4(0.7)$ & $8.8(4.4)$ & $0.6(0.3)$ & 116 \\
\hline
\end{tabular}
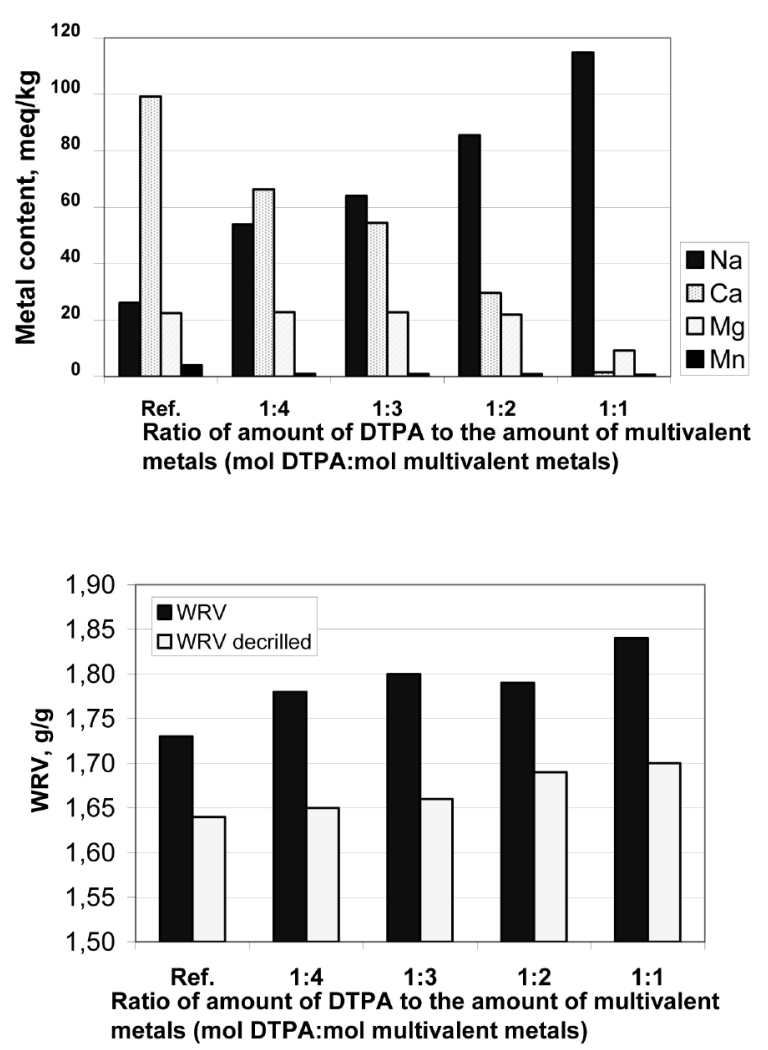

Fig 2. Metal content and WRV of unbleached pulp after different additions of DTPA based on the amount of multivalent metal ion content. 1:1 corresponds to a stochiometric amount of DTPA. The pH during ion-exchange was 10 and deionised water was used.

\section{Results and Discussion}

\section{Laboratory trials}

Effect of pH on ion-exchange

Ion-exchange was performed at four different $\mathrm{pH}$ levels in order to investigate how the removal of different metal ions depends upon the $\mathrm{pH}$ during the ion-exchange procedure. Table 2 shows that the removal of divalent ions was favoured by an increase in $\mathrm{pH}$. At $\mathrm{pH} 11$, divalent ions were largely replaced by $\mathrm{Na}^{+}$, but the results also show that it is sufficient to change the $\mathrm{pH}$ to 9 to achieve an ion-exchange of the pulp. In addition to the metal ions presented in the table, small amounts of other metal ions were also present in the pulp samples. The trace amounts of these metal ions are not given in the table. The table also shows that the metal content of the reference pulp exceeded the total charge $(116 \mathrm{mmol} / \mathrm{kg})$, which may be explained by the possible presence of oxides in addition to the charged groups or insufficient washing prior to metal analysis to remove DTPA. 

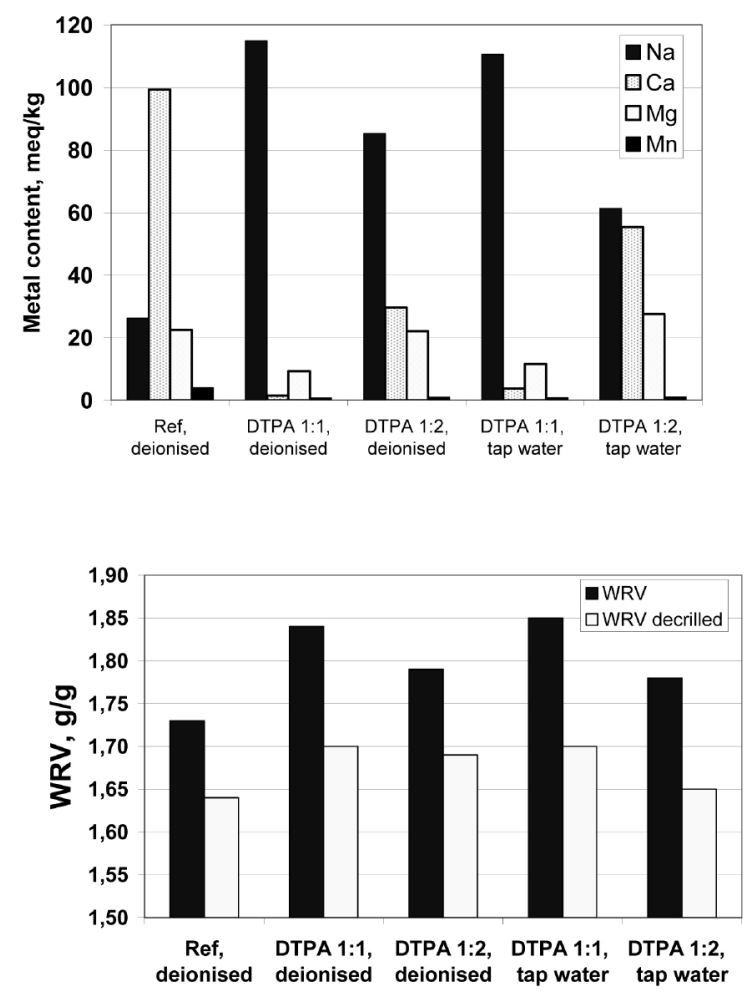

Fig 3. Metal content and WRV of unbleached washed pulps, ion-exchanged at two different DTPA ratios (1:1 and 1:2) and in deionised water and municipal water (tap water). The $\mathrm{pH}$ during ion exchange was 10.

\section{Amount of DTPA}

Four different amounts of DTPA were added to a fibre suspension. Fig 2 shows that an increase in the amount of DTPA led to an increase in the ion-exchange of the divalent ions by $\mathrm{Na}^{+}$as expected. At a ratio of the amount of DTPA to the amount of multivalent ions of $1: 2,70 \%$ of the calcium was removed from the pulp fibres. The content of manganese was reduced at all DTPA-charges, while the content of magnesium was affected to a lesser extent.

When the content of multivalent metals decreased, the WRV value of the pulp was slightly increased, but there was no direct correlation between the amount of DTPA and the WRV of the pulp fibres. The WRV values for the pulps after removal of the fines particles are also presented. They followed the same trends as the WRV for pulps with fines.

Ion-exchange in deionised water or municipal water In the laboratory, trials are usually performed with deionised water to avoid any differences in conductivity and composition that may occur in municipal water. Municipal waters also differ depending upon geographical location etc. However, it is of interest to study the ion exchange efficiency if the ion-exchange is performed in municipal water.

Fig 3 shows that, for the highest charge of DTPA, the content of sodium was approximately the same whether municipal water (tap water) or deionised water was used. At a DTPA charge of $50 \%$ (1:2), the content of calcium was higher in the pulp when the ion-exchange was

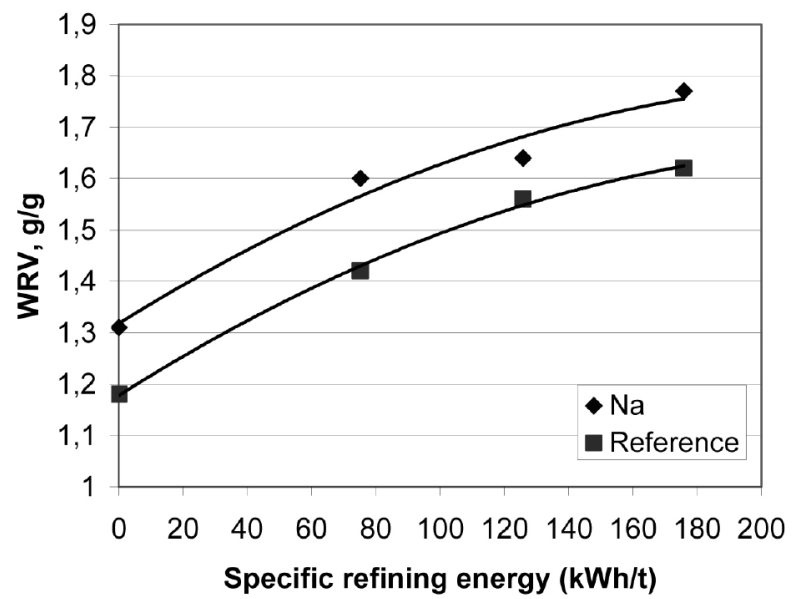

Fig 4. WRV versus specific refining energy for a reference kraft pulp and after ionexchange to the $\mathrm{Na}^{+}$- form.

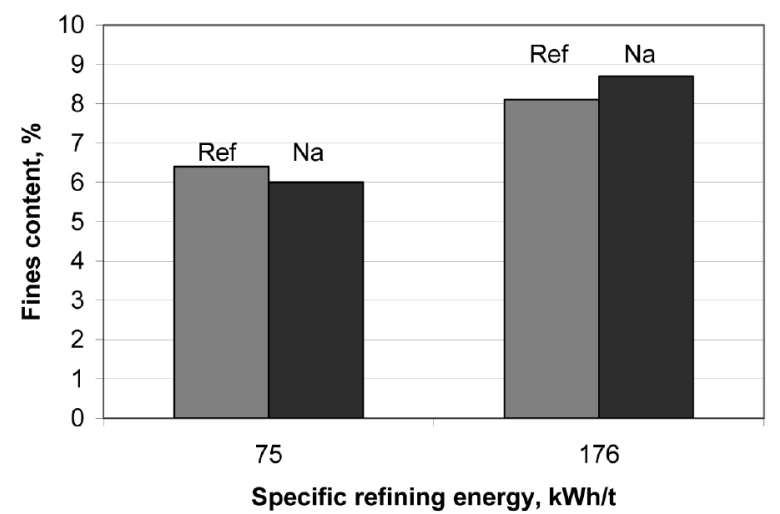

Fig 5. The fines content at two specific refining levels for the reference pulp and pulp refined in the $\mathrm{Na}^{+}$- form.

performed in municipal water. The corresponding values for the WRV for unrefined fibres show only small differences in WRV associated with whether the ion exchange was performed in deionised water or in municipal water.

\section{Pilot refining trial}

After evaluating the sensitivity towards different process conditions as described above, pilot refining and pilot papermaking trial were performed at EuroFEX.

The ion exchange and refining of the pulp converted into the $\mathrm{Na}^{+}$-form were done in softened water. For the reference pulp, municipal water from the water supply of Stockholm city was used. According to Table 1, the DTPA did remove all the multivalent ions and the treated pulp had a somewhat higher metal content than the untreated pulp which might be due to that all the residual DTPA was not removed before the metal analysis was performed. Despite the fact that the pulp was not ionexchanged to $100 \%$ the DTPA-treated pulp will be denoted $\mathrm{Na}^{+}$-form in the following text. The paper machine used municipal water which instantly converts the fibres back from the $\mathrm{Na}^{+}$-form into the $\mathrm{Ca}^{2+}$-form. The papermaking is thus performed in the $\mathrm{Ca}^{2+}$-form which makes this study comparable with the previous laboratory trial by Hammar et al. (2000), where the impact of different ionic forms on the beatability was investigated for an unbleached softwood pulp using a laboratory refiner. 


\section{Swelling}

The response in fibre swelling, measured as WRV, to the refining is shown in Fig 4. The WRV for the unrefined pulp fibres was higher for the pulp refined in the $\mathrm{Na}^{+}$-form than for the pulp fibres in the $\mathrm{Ca}^{2+}$ form which is in accordance with previous work done by Stone and Grignon (1979). The initial difference was maintained throughout the refining. In order to achieve a WRV of $1.6 \mathrm{~g} / \mathrm{g}, 90 \mathrm{kWh} / \mathrm{t}$ was required when the pulp was in the $\mathrm{Na}^{+}$-form, whereas the energy demand to reach this WRV for the untreated reference pulp was $160 \mathrm{kWh} / \mathrm{t}$.

The amount of fines was determined using the BDDJ method for two specific refining energy inputs and showed no significant difference between the two pulps, Fig 5. This indicates that the improved beatability of fibres in the $\mathrm{Na}^{+}$-form cannot be explained by any increase in fines content.

\section{Fibre properties}

The change of the counter-ions in the fibre matrix into the $\mathrm{Na}^{+}$-form changed their behaviour during refining slightly. Fig 6 shows the fibre length for unrefined pulp and for pulps refined at three different specific refining energies. The fibres were somewhat shortened in the pulp refined in the $\mathrm{Na}^{+}$-form. The fibres in the $\mathrm{Na}^{+}$-form are initially more swollen and soft and are therefore probably more sensitive to mechanical treatment at a specific energy input. It appears that refining in the $\mathrm{Na}^{+}$-form leads to more fibre length reduction, since the fibre length is shorter at a specific refining energy input. No difference was however found in the relation between tensile index and fibre length. Despite a decrease in fibre length, refining apparently introduce favourable structural changes that increase the tensile index. No significant difference in shape factor or fibre width, measured with the STFI FiberMaster, between the two ionic forms was observed in this trial (not shown).

\section{Paper properties}

As expected, the higher degree of swelling also affected the mechanical properties of the produced paper. Fig 7 show the mechanical properties of the paper for a given press-section linear load combination. The refining

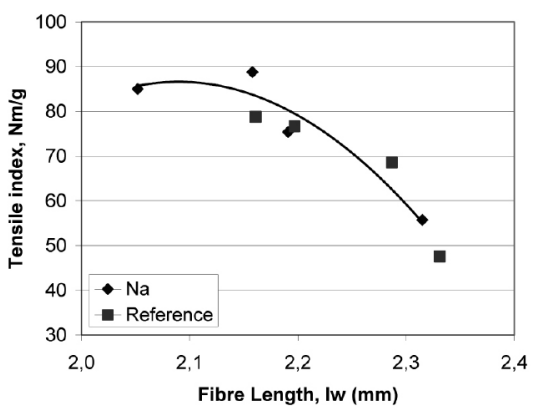

Fig 6. The fibre length vs specific refining energy and tensile index (as geometrical mean of MD and CD) vs fibre length for a reference kraft pulp after ion-exchange to the $\mathrm{Na}^{+}$-form.
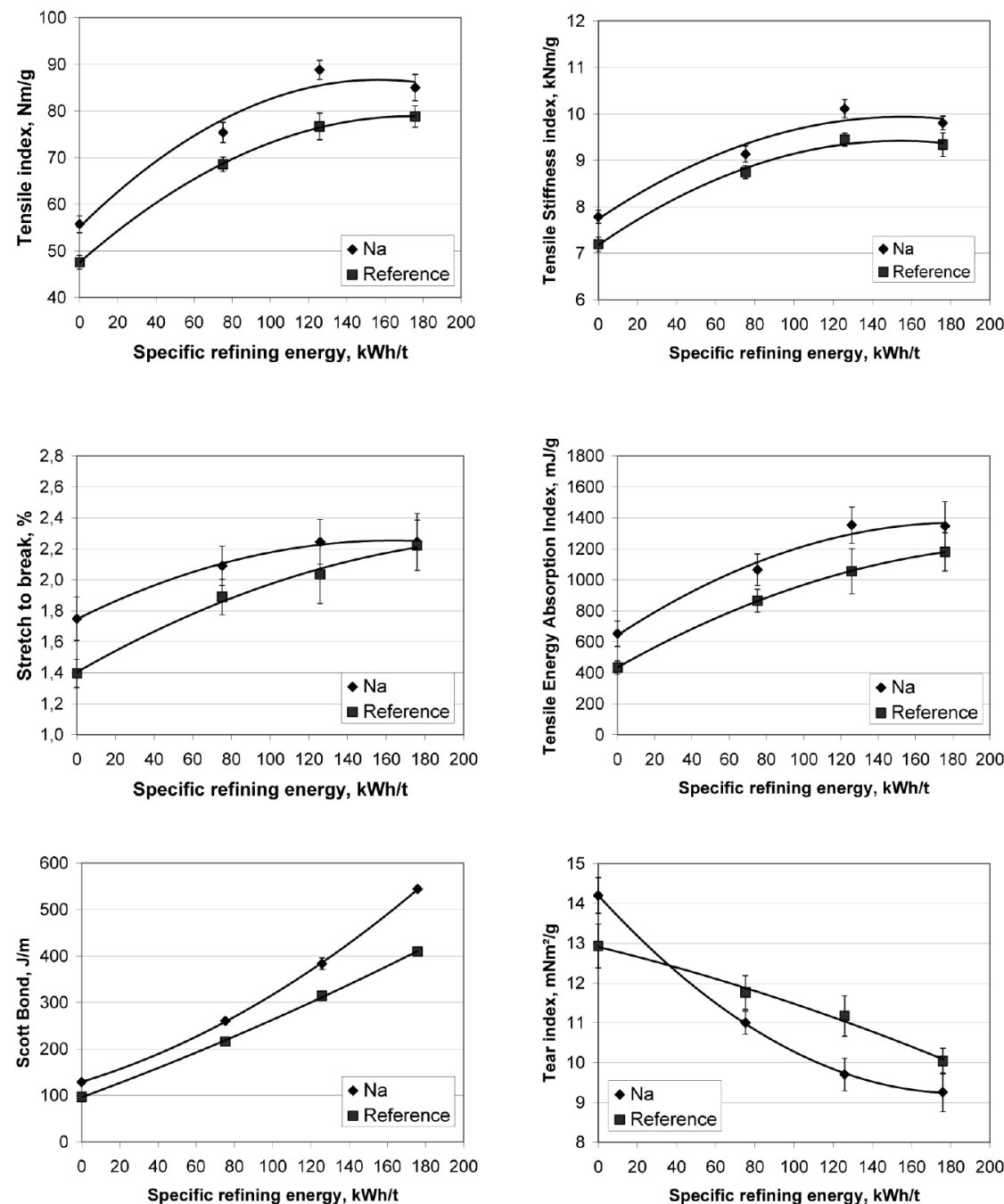

Fig 7. Paper properties (as geometrical mean of MD and CD) vs specific refining energy for a reference kraft pulp and after ion-exchange to the $\mathrm{Na}^{+}$-form for paper produced on EuroFEX. In this case, the linear loads in the presses were 60,100 and $500 \mathrm{kN} / \mathrm{m}$. The $95 \%$ confidence interval is shown by error bars.

energy required to reach a given tensile index level was reduced when the pulp was converted into the $\mathrm{Na}^{+}$-form prior to refining. For instance, to reach a tensile index of $75 \mathrm{Nm} / \mathrm{g}$ the specific energy demand was $125 \mathrm{kWh} / \mathrm{t}$ for the reference pulp, but only $65 \mathrm{kWh} / \mathrm{t}$ for the pulp in the $\mathrm{Na}^{+}$-form. The energy reduction was thus almost $50 \%$ in this particular example.

The tensile stiffness index, stretch to break and tensile energy absorption index at a given specific refining energy were also higher for the pulp refined in the $\mathrm{Na}^{+}$-form 
than for the reference pulp. The tear index was somewhat lower for the pulp refined in $\mathrm{Na}^{+}$-form, which is expected from the fibre length reduction. The improved relationship between the mechanical properties of the paper and the specific refining energy is in accordance with previous laboratory findings by Hammar et al. (2000).

An improved strength-density relation was found for fibres refined in the $\mathrm{Na}^{+}$-form as illustrated in Fig 8, where the tensile index and tensile energy absorption index are plotted as functions of density. The improvement in tensile index was nearly $10 \mathrm{Nm} / \mathrm{g}$ at a given density.

\section{Press dewatering}

The degree of swelling of pulp fibres is important not only for the mechanical properties of the paper but also for the runnability and production of paper on a paper machine. A more highly swollen fibre is normally more difficult to dewater, and this may sometimes create a bottleneck in the paper production when the drying capacity is limited.

The higher initial degree of swelling of the fibres in the $\mathrm{Na}^{+}$-form resulted in a lower solids content after the press section. Fig 9 shows the solids content after the press section for all the press combinations used in the trial. The general trend was for the reference paper to have a higher solids content at a given specific refining energy. If, on the other hand, the comparison was made at a given tensile strength, the solids content was more or less the same at a given press linear load combination.

\section{The effect on sheet formation}

Table 3 shows the formation number at different wavelengths vs specific refining energy. No differences could be seen between the reference pulp and the pulp refined in the $\mathrm{Na}^{+}$-form, indicating that the ionic forms in fibres do not influence the formation of the sheet. The formation numbers of the EuroFEX produced paper was in the same range as those of commercial sack papers grades.

\section{Conclusions}

This study shows that ion-exchange of fibres into the $\mathrm{Na}^{+}$-form can be done on a pilot-scale using a complexing agent such as DTPA. The results of the present pilotsingle stage refining trial confirm previous laboratory experiments where an energy reduction up to $50 \%$ to reach a given WRV or tensile index can be achieved by converting the fibre into the $\mathrm{Na}^{+}$-form prior to refining. It has also been shown that ion-exchanged pulp fibres can be run on EuroFex without any change in press dewatering, compared at a given tensile index of the paper.

The improved beatability of the pulps in the $\mathrm{Na}^{+}$-form

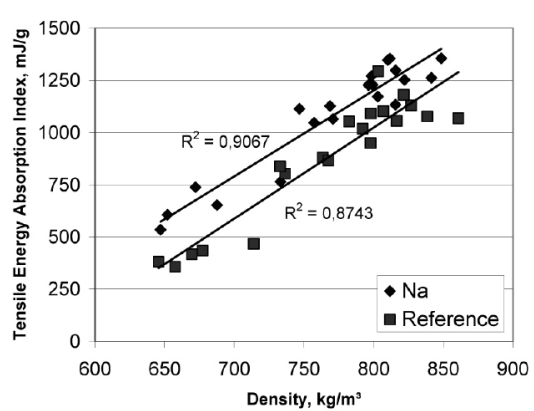

geometrical mean of MD and CD) versus density for a reference kraft pulp and after ionexchange into the $\mathrm{Na}^{+}$-form for paper produced on EuroFEX.

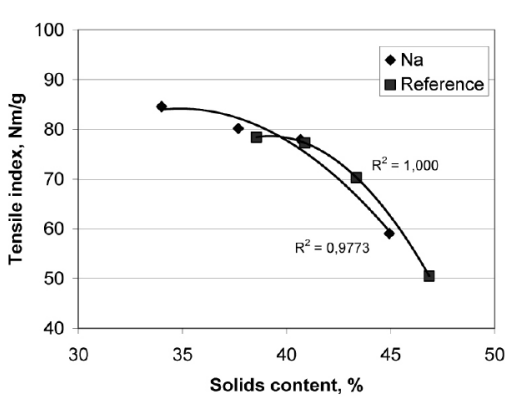

Fig 9. Left) The outgoing solids content after the press section for all the linear loads vs. specific refining energy input during refining for an unbleached kraft pulp refined in the $\mathrm{Na}^{+}$-form and the reference, refined in the $\mathrm{Ca}^{+}$form. Right) Tensile index (as geometrical mean of MD and CD) vs. solids content after the press section. In this case the linear load in the second press was $500 \mathrm{kN} / \mathrm{m}$ and in the third press $700 \mathrm{kN} / \mathrm{m}$.

Table 3. The normalized formation numbers in wavelength intervals for small-scale formation $F(0.3-3 \mathrm{~mm})$, large-scale formation $F(3-30 \mathrm{~mm})$ and the combined range $F(0.3-30 \mathrm{~mm})$.

\begin{tabular}{|c|c|c|c|c|c|c|}
\hline \multirow[b]{2}{*}{$\begin{array}{l}\text { Specific } \\
\text { refining } \\
\text { energy }\end{array}$} & \multicolumn{6}{|c|}{ Formation numbers } \\
\hline & $\begin{array}{c}F \\
\underset{(0.3-3 \mathrm{~mm})}{\mathrm{Na}^{+}}\end{array}$ & $\begin{array}{c}F \\
(0.3-3 \mathrm{~mm}) \\
\text { Ref }\end{array}$ & $\begin{array}{c}\mathrm{F} \\
\underset{(3-30 \mathrm{~mm})}{\mathrm{Na}^{+}}\end{array}$ & $\begin{array}{c}F \\
(3-30 \mathrm{~mm}) \\
\text { Ref }\end{array}$ & $\begin{array}{c}F \\
\underset{(0.3-30 ~ m m)}{\mathrm{Na}^{+}}\end{array}$ & $\begin{array}{c}F \\
(0.3-30 \mathrm{~mm}) \\
\operatorname{Ref}\end{array}$ \\
\hline 0 & 9.7 & 9.8 & 10.6 & 10.6 & 14.4 & 14.5 \\
\hline 75 & 9.5 & 9.5 & 10 & 10 & 13.8 & 13.8 \\
\hline 126 & 9.2 & 9.2 & 9.5 & 9 & 13.2 & 12.9 \\
\hline 176 & 8.9 & 8.9 & 8.7 & 8.7 & 12.5 & 12.5 \\
\hline
\end{tabular}

showed that the energy efficiency of beating is improved if the fibres are initially highly swollen, e.g converted into $\mathrm{Na}^{+}$-form. The improved beatability cannot be explained in terms of fines production since the production of fines at a given energy input was the same for the reference as for the pulp in the $\mathrm{Na}^{+}$-form. The conclusion must thus be that swelling, which is enhanced by ion exchange to $\mathrm{Na}^{+}$-form, is the main explanation of the improvement in beatability (in terms of both energy required to reach a certain WRV and strength properties). Furthermore, it would also be interesting to study whether fibre suspensions in different ionic forms have different rheological behaviours or have different fibrillation properties which might also be a part of the explanation of the increase in refining efficiency.

The practical implication of these results is that a fullscale application may be possible, and that it should then be possible to save significant amounts of energy, especially for papers made from unbleached pulps that usually demand a higher degree of refining to a achieve sufficient strength level. 


\section{Acknowledgement}

The authors express their thanks to Professor Lars Wågberg for valuable comments on the manuscript. Dr. Anthony Bristow is thanked for linguistic revision.

The authors also express their thanks for financial support from the Swedish Energy Agency (STEM) and the participating companies in the cluster Advanced Fibre Management in Stock Preparation, STFI-Packforsk research program 20032005.

\section{Literature}

Dence, C.W. and Omori, S. (1986): A survey of hydrogen peroxide bleaching of mechanical and chemimechanical pulp-factors affecting the brightness, Tappi J. 69(10), 120.

Flory, P.J. (1953): Principles of polymer chemistry, Cornell Univ. Press, Ithaca, N.Y. USA.

Hammar, L-Å., Bäckström, M. and Htun, M. (2000): Effect of the counterion on the beatability of unbleached kraft pulps, Nord. Pulp Paper Res. J. 15(3),189.

Karlsson, H., Fransson, P.-I. and Mohlin, U.-B. (1999): STFI FiberMaster, 6th International conference on new available technologies, Stockholm, Sweden, June 1-4, 1999, SPCl, Stockholm, Sweden, pp 367-374.

Katz, S., Beatson, R. and Scallan, A. (1984): The determination of strong and weak acidic groups in sulfite pulps, Svensk Papperstidning, 87(6), R48.

Lindström, T. (1992): Chemical factors affecting the behaviour of fibres during papermaking, Nord. Pulp Paper Res. J. 7(4),181.

Lindström, T. and Carlsson, G. (1978): The effect of chemical environment on fibre swelling, EUCEPA Symposium, Warszawa, Polen, September 5-8, 1978, pp 32-52.
Lindström, T. and Carlsson, G. (1982): The effect of chemical environment on fiber swelling, Svensk Papperstidning, 85(3), R14.

Lindström, T. and Kolman, M. (1982): Effect of pH and electrolyte concentration during beating and sheet forming on paper strength, Svensk Papperstidning, 85(15), R140.

Lloyd, J. and Horne, C. (1993): The determination of fibre charge and acidic groups of radiata pine pulps, Nord. Pulp Paper Res. J. 7(1), 48.

Mohlin, U-B. (1991): Low consistency beating - Laboratory evaluation contra industrial experience, PIRA Current and future technologies of refining 10-12 dec, pp 1-14.

Norman, B. (1986): The formation of paper sheets in Paper-Structures and Properties. Edited by J.A. Bristow and P Kolseth, Marcel Dekker Inc, New York, pp 124-150.

$\mathrm{Pu}$, Q. and Sarkanen, K. (1989): Donnan equilibria in wood-alkali interactions. Part I. Quantitative determinations of carboxyl-, carboxylester and phenolic hydroxyl groups, J. Wood Chem. Techn. 9(3),293.

Rigdahl, M., Bäckström, M., Hedström, C-G., Norman, B., Kilian, M. and Talja, R. (2000): Impulse technology on the Eurofex machine, Tappi J. 83(8),11.

Roding, S. and Norman, B. (1986): FEX, the new STFI experimental paper machine, Tappi J. 68(5),94.

Scallan, A.M. (1983): The effect of acidic groups on the swelling of pulps: a review, Tappi J. 66(11),73.

Scallan, A.M. and Grignon, J. (1979): The effect of cations on pulp and paper properties, Svensk Papperstidning, 82(2), 40.

Manuscript received August 15, 2008 Accepted January 22, 2009 